\title{
A deterministic inventory model for deteriorating items with selling price dependent demand and three-parameter Weibull distributed deterioration
}

\author{
Asoke Kumar Bhunia ${ }^{a}$ and Ali Akbar Shaikh ${ }^{b^{*}}$
}

${ }^{a}$ Department of Mathematics, The University of Burdwan, Burdwan - 713104, West Bengal, India

${ }^{b}$ Department of Mathematics, Krishnagar Govt. College, Krishnagar-741101, West Bengal, India

\section{CHR O N I C L E A B S T RA C T}

Article history:

Received November 22013

Received in Revised Format 10

January 2014

Accepted February 82014

Available online

February 212014

Keywords:

Inventory

Deterioration

Weibull distribution

Variable demand

Partially backlogged shortage

Non-linear programming

\begin{abstract}
In this paper, an attempt is made to develop two inventory models for deteriorating items with variable demand dependent on the selling price and frequency of advertisement of items. In the first model, shortages are not allowed whereas in the second, these are allowed and partially backlogged with a variable rate dependent on the duration of waiting time up to the arrival of next lot. In both models, the deterioration rate follows three-parameter Weibull distribution and the transportation cost is considered explicitly for replenishing the order quantity. This cost is dependent on the lot-size as well as the distance from the source to the destination. The corresponding models have been formulated and solved. Two numerical examples have been considered to illustrate the results and the significant features of the results are discussed. Finally, based on these examples, the effects of different parameters on the initial stock level, shortage level (in case of second model only), cycle length along with the optimal profit have been studied by sensitivity analyses taking one parameter at a time keeping the other parameters as same.
\end{abstract}

(C) 2014 Growing Science Ltd. All rights reserved

\section{Introduction}

According to the existing literature of inventory control system, most of the inventory models have been developed under the assumption that the life time of an item is infinite while it is in storage i.e., an item once in stock remains unchanged and fully usable for satisfying future demand. In real life situation, this assumption is not always true due to the effect of deterioration in the preservation of commonly used physical goods like wheat, paddy or any other type of food grains, vegetables, fruits, drugs, pharmaceuticals, etc. A certain fraction of these goods are either damaged or decayed or vaporized or affected by some other factors, etc. and are not in a perfect condition to satisfy the demand. As a result, the loss due to this natural phenomenon (i.e., the deterioration effect) can't be ignored in the analysis of the inventory system. Ghare and Schrader (1963) first developed an inventory model for exponentially decaying inventory. Then Emmons (1968) proposed this type of model with variable deterioration, which follows two-parameter Weibull distribution. These models were extended and improved by several researchers, viz. Covert and Philip (1973), Giri et al. (2003), Ghosh and * Corresponding author.

E-mail: bhuniaak@rediffmail.com (A. A. Shaikh) 
Chaudhari (2004). On the other hand, Chakrabarty et al. (1998), Giri et al.(1999), Sana et al. (2004), Sana and Chaudhari (2004) and others developed inventory models for deteriorating items with thereparameter weibull distributed deterioration. Misra (1975) developed an EOQ model with weibull deterioration rate for perishable product without considering shortages. These investigations were followed by several researchers like, Deb and Chaudhari (1986), Giri et. al. (1996), Goswami and Chaudhari (1991), Mandal and Phaujdar (1989a), Padmanabhan and Vrat (1995), Pal et al.(1993), Mandal and Maiti (1997), Goyal and Gunasekaran (1995), Sarkar et al.(1997), Bhunia and Maiti (1998a,1998b), Pal et al. (2005, 2006), Mishra and Tripathy (2010), Kawale and Bansode (2012), Bhunia et al. (2013a, 2013b), Sharma and Chaudhary (2013), Amutha and Chandrasekaran (2013) etc., where a time-proportional deterioration rate was considered.

In the present competitive market, the effect of marketing policies and conditions such as the price variations and the advertisement of an item change its demand pattern amongst the public. The propaganda and canvassing of an item by advertisement in the well-known media such as Newspaper, Magazine, Radio, T. V., Cinema, etc. and also through the sales representatives have a motivational effect on the people to buy more. Also, the selling price of an item is one of the decisive factors in selecting an item for use. It is commonly observed that lower selling price causes increase in demand whereas higher selling price has the reverse effect. Hence, it can be concluded that the demand of an item is a function of displayed inventory in a show-room, selling price of an item and the advertisement expenditures frequency of advertisement, Very few OR researchers and practitioners studied the effects of price variations and the advertisement on the demand rate of items. Kotler (1971) incorporated marketing policies into inventory decisions and discussed the relationship between economic order quantity and pricing decision. Ladany and Sternleib (1974) studied the effect of price variation on selling and consequently on EOQ. However, they did not consider the effect of advertisement. Subramanyam and Kumaraswamy (1971), Urban (1992), Goyal and Gunasekaran (1995), Abad (1996) and Luo (1998), Pal et al. (2007), Bhunia and Shaikh (2011) developed inventory models incorporating the effects of price variations and advertisement on demand rate of an item.

When a purchasing manager places an order of items, it is important to realize that different types of costs including the transportation cost of the items should be taken into account. Therefore, the inventory and transportation costs are dependent to each other when the transportation cost is involved in inventory replenishment, It is well known that different transportation models have different speed, reliability and cost characteristics. In most of the existing research, the transportation cost is not considered separately, it is included in the replenishment cost which is independent of the order quantity. In realistic situation, the transportation cost is not independent of the ordered quantity. As a result, this cost cannot be ignored in the analysis of inventory system. Recently, very few researchers considered this cost into the analysis of lot-size determination. Baumol and Vinod (1970) first considered an inventory model of freight transport where by ordered quantity and transportation alternative can jointly be determined. Constable and Whybark (1978) assumed that the transportation cost per unit is independent of the order quantities. Buffa and Munn (1989) developed the model considering the transportation per unit to be a negative exponential function of the order quantity. Anily and Federgruin (1990) have considered the transportation cost in terms of truck loading cost. Krishnawamy et al. (1995) developed an EOQ model considering the transportation cost both for deterministic and stochastic demand cases. In these models, transportation cost per unit for the mode of transport (transport vehicle) is dependent on the quantity of the product. Recently, Pal et al. (2006) and Mondal et al. (2007) considered this cost under the assumption that the transportation cost is constant for transport vehicle ( of a given capacity) even if the quantity shipped is less than a transport vehicle load by some quantity.

In this paper, we have developed two inventory models for deteriorating items with variable demand dependent on the selling price of items and frequency of advertisement of items. In the first model, stock-out situation is not allowed whereas in the second, it is allowed and partially backlogged with a 
variable rate dependent on the duration of waiting time up to the arrival of next lot. In both the models, the deterioration rate follows a three-parameter Weibull distribution and the transportation cost is considered explicitly for replenishing the order quantity. The corresponding models have been formulated and solved by considering the transportation cost for replenishing the items. Two numerical examples have been given to illustrate the results and the significant features of the result are discussed. Finally, based on these examples, the effects of different parameters on the initial stock level, shortage level (in case of second model only), cycle length along with the optimal profit, sensitivity analyses have been performed considering one parameter at a time keeping other parameters at their original values.

\section{Assumptions and Notations}

The following assumptions and notations are used to develop the proposed model:

(i) Replenishments are instantaneous with a known and constant lead time.

(ii) The entire lot is delivered in one batch.

(iii) The inventory planning horizon is infinite and the inventory system involves only one item and one stocking point.

(iv) The deterioration occurs when the item is effectively in-stock and its rate follows a threeparameter Weibull distribution.

(v) The deteriorated units are not replaced.

(vi) The replenishment cost (ordering cost) is constant and does not include the transportation cost for replenishing the item.

(vii) $A$ be the frequency of advertisement in the cycle length.

(viii) The inventory carrying cost, $C_{1}$ per unit per unit time, shortage cost, $C_{2}$ per unit per unit time, the purchase cost, $C_{3}$ per unit, the ordering cost, $C_{4}$ per order, the advertisement $\operatorname{cost} C_{5}$ per advertisement and the selling price, $p$ are known and constants.

(ix) $\alpha, \beta, \gamma$ be the parameters of the Weibull distribution whose probability density function is $f(t)=\alpha \beta(t-\gamma)^{\beta-1} \exp \left\{-\alpha(t-\gamma)^{\beta}\right\}$

(x) The instantaneous rate of deterioration of the on-hand in any time $t$ is $\theta(t)$ which obeys the three -parameter Weibull distribution.

So, $\theta(t)=\frac{f(t)}{1-F(t)}=\alpha \beta(t-\gamma)^{\beta-1} \quad$ where $\quad 0<\alpha<<1, \quad \beta>0, \gamma \geq 0$ and $F(t) \quad$ is the distribution function of Weibull distribution.

For $\beta=1, \theta(t)$ is constant and the Weibull distribution reduces to exponential distribution

$\beta>1, \theta(t)$ is an increasing function of $t$,

$\beta<1, \theta(t)$ is a decreasing function of $t$.

For $\gamma=0$, the three-parameter Weibull distribution reduces to two parameter Weibull distribution.

(xi) The demand rate $D(A, p)$ is dependent on selling price $(p)$ of an item and the frequency of advertisement $(A)$. We assume it as follows: $D(A, p)=A^{v}(a-b p), a, b, v>0$.

(xii) $R$ be the maximum shortage level.

(xiii) $m(>1)$ be the mark-up i.e., $p=m C_{3}$.

(xiv) The capacity of a transportation vehicle is $k$ units.

(xv) $L$ be the distance between the shop and the source of the items/commodities from where items/commodities to be transported.

(xvi) $C_{t}$ be the transportation cost for full load of the transport vehicle and $C_{t F}$ be the transportation cost per unit item. 
(xviii) $U$ be the upper break point, some quantity loss than $k$ but more than $U$, the transportation cost for whole quantity is $C_{t}$.

Hence $U=\frac{C_{t}}{C_{t F}}(<k)$ where $\left[\frac{C_{t}}{C_{t F}}\right]$ represents the greatest integer value which is less then or equal to $C_{t} / C_{t F}$.

\section{Inventory model without shortage}

Initially, an enterprise purchases an amount of stock of $S$ units of the item. This amount will be depleted due to deterioration of item and also to meet up the customers' demand. Let $q(t)$ be the instantaneous inventory level at any time $t \geq 0$. Then the inventory level $q(t)$ at any time $t$ satisfies the differential equation as follows:

$\frac{d q(t)}{d t}+\theta(t) q(t)=-D(A, p), \quad 0 \leq t \leq T$

with the boundary conditions

$q(t)=S$ at $t=0$

and

$q(t)=0$ at $t=T$

Using the condition (3), the solution of the differential Eq. (1) is given by

$$
q(t)=D(A, p) e^{-\alpha(t-\gamma)^{\beta}} \int_{t}^{T} e^{\alpha(t-\gamma)^{\beta}} d t
$$

From Eq. (2), we have

$$
S=D(A, p) e^{-\alpha(-\gamma)^{\beta}} \int_{0}^{T} e^{\alpha(t-\gamma)^{\beta}} d t
$$

During the inventory cycle, deteriorated units are to be separated. The amount of inventory that has deteriorated during the cycle can be derived by integrating the product of the deterioration rate and the inventory level over the entire cycle i.e., the total number of deteriorated units is given by

$$
D^{\prime}=\int_{0}^{T} \theta(t) q(t) d t
$$

However, $D^{\prime}$ can be derived from the difference between the initial stock and the total selling amount during the cycle, i.e.,

$$
D^{\prime}=S-\int_{0}^{T} D(A, p) d t=S-D(A, p) T
$$


Now, the total inventory holding cost $C_{\text {hol }}$ is given by

$$
C_{\text {hol }}=C_{1} \int_{0}^{T} q(t) d t
$$

where

$$
\begin{aligned}
\int_{0}^{T} q(t) d t=\frac{T^{2}}{2} & +\frac{\alpha^{2} T(T-\gamma)^{2 \beta+1}}{2(2 \beta+1)}-\frac{\alpha(T-\gamma)^{\beta+2}}{(\beta+1)(\beta+2)}-\frac{\alpha^{2}(T-\gamma)^{2 \beta+2}}{2(2 \beta+1)(2 \beta+2)} \\
& -\frac{\alpha^{2}(T-\gamma)^{2 \beta+2}}{(\beta+1)^{2}}+\alpha(-\gamma)^{\beta}\left\{\frac{T^{2}}{2}-\left(\frac{\beta}{\gamma}\right) \frac{T^{3}}{3}\right\} \\
& +\frac{\alpha^{2}(T-\gamma)^{2 \beta+2}}{(\beta+1)(2 \beta+2)}+\frac{\alpha^{2} T(T-\gamma)^{2 \beta+1}}{2(2 \beta+1)}-\frac{\alpha^{2}(-\gamma)^{2 \beta}}{2}\left\{\frac{T^{2}}{2}-\left(\frac{2 \beta}{\gamma}\right) \frac{T^{3}}{3}\right\} \\
& +\frac{\alpha(-\gamma)^{\beta+2}}{(\beta+1)(\beta+2)}+\frac{\alpha^{2}(-\gamma)^{2 \beta+2}}{2(2 \beta+1)(2 \beta+2)}+\frac{\alpha T(-\gamma)^{\beta+1}}{(\beta+1)} \\
& +\frac{\alpha^{2}(T-\gamma)^{\beta+1}(-\gamma)^{\beta+1}}{(\beta+1)^{2}}-\frac{\alpha^{2}(-\gamma)^{2 \beta+2}}{(\beta+1)(2 \beta+2)}-\frac{\alpha^{2} T(-\gamma)^{2 \beta+1}}{2(2 \beta+1)}
\end{aligned}
$$

neglecting the powers of $\alpha$ higher than two as $0<\alpha<<1$. The total advertisement cost is the product of the number of advertisement and the cost per advertisement i.e., $C_{a d v}=C_{5} \mathrm{~A}$

When the ordered quantity is greater than one integral transport vehicle load, the ordered quantity $Q$ can be expressed as $Q=n k+k_{1} q$ where $n=0$ or any positive integer ; $k_{1}=0$ or 1 and $q<k$.

In that case, two situations may arise:

$\begin{array}{ll}\text { (i) } n k<Q \leq n k+U & \text { (ii) } n k+U<Q \leq(n+1) k\end{array}$

Hence the total transportation cost is given by

$$
\begin{aligned}
C_{\text {tran }} & =n C_{t}+(Q-n k) C_{t F}, & & \text { where } n k<Q \leq n k+U \\
& =(n+1) C_{t}, & & \text { where } n k+U<Q \leq(n+1) k
\end{aligned}
$$

The total $\operatorname{cost}(T C)$ of the system is given by

$T C=<$ ordering cost $>+<$ purchasing cost $>+<$ inventory holding cost $>+<$ advertisement cost $>+$ $<$ transportation cost $>$

$$
=C_{4}+C_{3} \cdot S+C_{1} \int_{0}^{T} q(t) d t+C_{5} A+C_{\text {tran }}
$$

The net profit $(X)$ for the entire system is the difference between the sale revenue per cycle and the total cost of the system i.e.,

$$
X=p A^{v}(a-b p) T-T C
$$


Therefore the profit function $Z(m, n, A, T)$ (average profit per unit time for the entire cycle) of the inventory system is given by

$$
\begin{aligned}
& Z(m, n, A, T)=\frac{X}{T} \\
& \text { i.e., } \quad Z(m, n, A, T)=\left[p A^{v}(a-b p)-\left\{C_{4}+C_{3} . S+C_{1} \int_{0}^{T} q(t) d t+C_{5} A+C_{\text {tran }}\right\}\right] / T
\end{aligned}
$$

Here the profit function is a function of two continuous variables $m, T$ and two integer variables $n, A$.

Proposition: The profit function $Z$ is an increasing function of $m$ for any feasible values of $n, A$ and $T$.

Proof: Clearly $\frac{d Z}{d m}>0$ for $a>2 b p$. This condition gives the increasing property of the profit function $Z$.

Hence our problem is to determine the optimal values of $n, A, T$ and $S$ by solving the following mixed integer nonlinear optimization problem.

$$
\begin{aligned}
& \text { Maximize } Z(n, A, T) \\
& \text { subject to } n, A, T>0 \text { and } n, A \text { are integers }\} \\
& C_{\text {tran }}=n C_{t}+(S-n k) C_{t F} \text {, when } n k<S \leq n k+U \\
& =(n+1) C_{t}, \quad \text { when } \quad n k+U<S \leq(n+1) k
\end{aligned}
$$

The above problem can be solved by using the well-known LINGO 8.0 software. However, the optimal solution of the above problem can be obtained with the help of the following algorithm.

\section{Algorithm 1}

Step-1: Input all the parameters.

Step-2: Calculate the value of $U$.

Step-3: Solve the problem (10) by taking the transportation cost for first situation $(n k<S \leq n k+U)$

Step-4: If $S$ lies in the interval $(n k<S \leq n k+U)$, then this is the optimal policy and go to Step-7. Otherwise, go to Step-5.

Step-5: Solve the problem (10) by taking the transportation cost for second situation $(n k+U<S \leq(n+1) k)$.

Step-6: If $S$ lies in the interval $(n k+U<S \leq(n+1) k)$, then this is the optimal policy.

Step-7: Stop.

\section{Numerical Example}

To illustrate the developed model, an example with the following data has been considered.

$C_{1}=\$ 1.5$ per unit per unit time, $C_{3}=\$ 8$ per unit, $C_{4}=\$ 250$ per order, $C_{5}=\$ 50$ per advertisement, $C_{t}=\$ 100$ per transport vehicle, $C_{t F}=\$ 1.25$ per unit, $\alpha=0.05, \beta=2, \gamma=2.5, a=250, b=0.3, k$ $=100$ units. $L=50 \mathrm{~km}, v=0.1$. Though the values of different parameters are not collected from any case study, the values considered here are realistic.

According to our developed algorithm (i.e., Algorithm 1) of the proposed inventory system, the optimal solution has been obtained with the help of well known LINGO software for different values of $m$. The optimum values of $n, A, T, S$ along with the maximum average profit are displayed in Table 1 . 
Table 1

Optimal solution for different values of mark-up rate $m$

\begin{tabular}{ccccc}
\hline$m$ & $A$ & $S$ & $T$ & $Z$ \\
\hline 1.25 & 4 & 1300.00 & 5.4787 & 326.1550 \\
1.27 & 5 & 1300.00 & 5.3887 & 372.4020 \\
1.30 & 6 & 1400.00 & 5.61664 & 441.7629 \\
1.32 & 7 & 1400.00 & 5.5551 & 489.6958 \\
1.35 & 8 & 1400.00 & 5.5021 & 561.5950 \\
\hline
\end{tabular}

\section{Sensitivity Analysis}

For the given example mentioned earlier, sensitivity analysis has been performed to study the effect of changes (under or over estimation) of different parameters like demand, deterioration parameters and mark-up rate on maximum initial stock level, cycle length, frequency of advertisement along with the maximum profit of the system. This analysis is carried out by changing (increasing and decreasing) the parameters from $-20 \%$ to $+20 \%$, taken one or more parameters at a time and making the other parameters at their original values. The results of this analysis are shown in Table 2.

\section{Table 2}

Sensitivity analysis with respect to different parameters

\begin{tabular}{|c|c|c|c|c|c|}
\hline \multirow[b]{2}{*}{ Parameter } & \multirow[b]{2}{*}{$\%$ changes of parameters } & \multirow[b]{2}{*}{$\%$ changes in $Z^{*}$} & \multirow[b]{2}{*}{$\mathrm{A}^{*}$} & \multicolumn{2}{|c|}{$\%$ changes in } \\
\hline & & & & $\mathrm{S}^{*}$ & $\mathrm{~T}^{*}$ \\
\hline \multirow{4}{*}{$C_{l}$} & -20 & 14.83 & 7 & -7.14 & -6.48 \\
\hline & -10 & 7.35 & 6 & -7.14 & -5.36 \\
\hline & 10 & -6.53 & 6 & 0 & 0 \\
\hline & 20 & -12.91 & 5 & 0 & 1.31 \\
\hline \multirow{4}{*}{$C_{3}$} & -20 & -47.33 & 4 & 0 & 2.73 \\
\hline & -10 & -24.08 & 5 & 0 & 1.22 \\
\hline & 10 & 25.14 & 7 & -7.14 & -6.39 \\
\hline & 20 & 50.87 & 8 & -7.14 & -7.27 \\
\hline \multirow{4}{*}{$C_{4}$} & -20 & 2.12 & 6 & -7.14 & -5.35 \\
\hline & -10 & 1.05 & 6 & -7.14 & -5.36 \\
\hline & 10 & -1.01 & 6 & 0 & 0 \\
\hline & 20 & -2.02 & 6 & 0 & 0 \\
\hline \multirow{4}{*}{$C_{5}$} & -20 & 2.97 & 8 & 0 & -2.07 \\
\hline & -10 & 1.44 & 7 & 0 & -1.11 \\
\hline & 10 & -1.03 & 5 & -7.14 & -4.04 \\
\hline & 20 & -2.08 & 5 & -7.14 & -4.04 \\
\hline \multirow{4}{*}{$a$} & -20 & -24.52 & 5 & -21.43 & 0.24 \\
\hline & -10 & -12.17 & 5 & -14.29 & -2.1 \\
\hline & 10 & 12.69 & 7 & 7.14 & -3.1 \\
\hline & 20 & 25.24 & 7 & 14.29 & -4.79 \\
\hline \multirow{4}{*}{$b$} & -20 & 0.34 & 6 & 0 & -0.18 \\
\hline & -10 & 0.18 & 6 & 0 & -0.09 \\
\hline & 10 & -0.16 & 6 & -7.14 & -5.27 \\
\hline & 20 & -0.3 & 6 & -7.14 & -5.18 \\
\hline \multirow{4}{*}{$v$} & -20 & -3.79 & 5 & -7.14 & -1.71 \\
\hline & -10 & -1.86 & 5 & -7.14 & -2.87 \\
\hline & 10 & 2.51 & 7 & 0 & -2.52 \\
\hline & 20 & 4.89 & 8 & 7.14 & -0.1 \\
\hline \multirow{4}{*}{$\alpha$} & -20 & -52.42 & 2 & -50 & -43.58 \\
\hline & -10 & -28.87 & 4 & -14.29 & -9.68 \\
\hline & 10 & 31.38 & 8 & 0 & -0.87 \\
\hline & 20 & 64.14 & 10 & 7.14 & 3.41 \\
\hline \multirow{4}{*}{$\gamma$} & -20 & -61.12 & 2 & -57.14 & -53.28 \\
\hline & -10 & -40.67 & 3 & -35.71 & -30.18 \\
\hline & 10 & 62.12 & 12 & 21.43 & 15.34 \\
\hline & 20 & 126.39 & 13 & 7.14 & 10.37 \\
\hline
\end{tabular}




\section{Inventory model with shortages}

In this model, shortages, if any, are allowed and partially backlogged. During the shortage period, the backlogging rate is dependent on the length of the waiting time up to the arrival of fresh lot. Considering this situation, the rate is defined as $[1+\delta(T-t)]^{-1}, \delta>0$. In this model, it is assumed that after fulfilling the backorder quantity, the on-hand inventory level is $S$ at $t=0$ and it declines continuously up to the time $t=t_{1}$ when it reaches the zero level. The decline in inventory during the closed time interval $0 \leq t \leq t_{1}$ occurs due to the customer's demand and deterioration of the item. After the time $t=t_{1}$, shortage occurs and it accumulates at the rate $[1+\delta(T-t)]^{-1},(\delta>0)$ up to the time $t=T$ when the next lot arrives. At time $t=T$, the maximum shortage level is $R$. This entire cycle then repeats itself after the cycle length $T$.

Let $q(t)$ be the instantaneous inventory level at any time $t \geq 0$. Then the inventory level $q(t)$ at any time $t$ satisfies the differential equations as follows,

$$
\begin{aligned}
& \frac{d q(t)}{d t}+\theta(t) q(t)=-D(A, p), \quad 0 \leq t \leq t_{1} \\
& \frac{d q(t)}{d t}=\frac{-D(A, p)}{1+\delta(T-t)}, \quad t_{1}<t \leq T
\end{aligned}
$$

with the boundary conditions

$$
q(t)=S \text { at } t=0, q(t)=0 \text { at } t=t_{1} .
$$

and

$$
q(t)=-R \text { at } t=T \text {. }
$$

Also, $q(t)$ is continuous at $t=t_{1}$.

Using the conditions (3) and (4), the solutions of the differential equations (11)-(12) are given by

$$
\begin{array}{rlr}
q(t) & =D(A, p) e^{-\alpha(t-\gamma)^{\beta}} \int_{t}^{t_{1}} e^{\alpha(t-\gamma)^{\beta}} d t, & 0 \leq t \leq t_{1} \\
& =\frac{D(A, p)}{\delta} \log |1+\delta(T-t)|-R, \quad t_{1}<t \leq T
\end{array}
$$

From Eq. (12), we have $q(t)=S$ at $t=0$.

Then,

$$
S=D(A, p) e^{-\alpha(-\gamma)^{\beta}} \int_{0}^{t_{1}} e^{\alpha(t-\gamma)^{\beta}} d t
$$

From the continuity condition, we have

$$
R=\frac{D(A, p)}{\delta} \log \left|1+\delta\left(T-t_{1}\right)\right|
$$

Now the total inventory holding cost for the entire cycle is given by 


$$
C_{h o l}=C_{1} \int_{0}^{t_{1}} q(t) d t
$$

where

$$
\begin{array}{r}
\int_{0}^{t_{1}} q(t) d t=\frac{t_{1}^{2}}{2}+\frac{\alpha^{2} t_{1}\left(t_{1}-\gamma\right)^{2 \beta+1}}{2(2 \beta+1)}-\frac{\alpha\left(t_{1}-\gamma\right)^{\beta+2}}{(\beta+1)(\beta+2)}-\frac{\alpha^{2}\left(t_{1}-\gamma\right)^{2 \beta+2}}{2(2 \beta+1)(2 \beta+2)} \\
\frac{-\alpha^{2}\left(t_{1}-\gamma\right)^{2 \beta+2}}{(\beta+1)^{2}}+\alpha(-\gamma)^{\beta}\left\{\frac{t_{1}^{2}}{2}-\left(\frac{\beta}{\gamma}\right) \frac{t_{1}^{3}}{3}\right\} \\
+\frac{\alpha^{2}\left(t_{1}-\gamma\right)^{2 \beta+2}}{(\beta+1)(2 \beta+2)}+\frac{\alpha^{2} t_{1}\left(t_{1}-\gamma\right)^{2 \beta+1}}{2(2 \beta+1)}-\frac{\alpha^{2}(-\gamma)^{2 \beta}}{2}\left\{\frac{t_{1}^{2}}{2}-\left(\frac{2 \beta}{\gamma}\right) \frac{t_{1}^{3}}{3}\right\} \\
+\frac{\alpha(-\gamma)^{\beta+2}}{(\beta+1)(\beta+2)}+\frac{\alpha^{2}(-\gamma)^{2 \beta+2}}{2(2 \beta+1)(2 \beta+2)}+\frac{\alpha t_{1}(-\gamma)^{\beta+1}}{(\beta+1)} \\
+\frac{\alpha^{2}\left(t_{1}-\gamma\right)^{\beta+1}(-\gamma)^{\beta+1}}{(\beta+1)^{2}}-\frac{\alpha^{2}(-\gamma)^{2 \beta+2}}{(\beta+1)(2 \beta+2)}-\frac{\alpha^{2} t_{1}(-\gamma)^{2 \beta+1}}{2(2 \beta+1)}
\end{array}
$$

Again, the total shortage cost $C_{S h o}$ over the entire cycle is given by

$$
C_{\text {sho }}=\left(R+\frac{D(A, p)}{\delta}\right)\left(T-t_{1}\right)-\frac{D(A, p)}{\delta^{2}}\left[\left(1+\delta\left(T-t_{1}\right)\right) \log \left|1+\delta\left(T-t_{1}\right)\right|\right]
$$

Hence the total inventory $\operatorname{cost}(T C)$ of the system is given by

$T C=<$ ordering cost $>+<$ purchasing cost $>+<$ inventory holding cost $>+<$ advertisement cost $>+$ $<$ transportation cost $>+<$ inventory shortage cost $>$

$$
=C_{4}+C_{3}(S+R)+C_{1} \int_{0}^{t_{1}} q(t) d t+C_{5} A+C_{\text {tran }}+C_{\text {sho }}
$$

Now, the net profit $(X)$ for the entire system is given by

$$
X=p A^{v}(a-b p) T-T C .
$$

Therefore, the profit function $Z\left(m, n, A, t_{1}, T\right)$ (average profit per unit time for the entire cycle) of the inventory system is given by $Z\left(m, n, A, t_{1}, T\right)=\frac{X}{T}$

i.e., $Z\left(m, n, A, t_{1}, T\right)=\left[p A^{v}(a-b p)-\left\{C_{4}+C_{3}(S+R)+C_{1} \int_{0}^{t_{1}} q(t) d t+C_{5} A+C_{\text {tran }}+C_{\text {sho }}\right\}\right] / T$

Here the profit function is a function of three continuous variables $m, t_{1}, T$ and two integer variables $n$, $A$. Clearly, the above function is an increasing function with respect to $m$. Hence our problem is to determine the optimal values of $n, A, t_{l}, T$ and $S$ by solving the following mixed integer nonlinear optimization problem.

$\left.\begin{array}{l}\text { Maximize } Z\left(n, A, t_{1}, T\right) \\ \text { subject to } \mathrm{t}_{1}<T, n, A, t_{1}>0 \text { and } n, A \text { are integers }\end{array}\right\}$ 
where

$$
\begin{aligned}
C_{\text {tran }} & =n C_{t}+(S+R-n k) C_{t f} \text { when } n k<S+R \leq n k+U \\
& =(n+1) C_{t} \quad \text { when } n k+U<S+R \leq(n+1) k
\end{aligned}
$$

This is a non-linear optimization problem. The optimal solution of the this problem can be obtained with the help of the following algorithm using LINGO software.

\section{Algorithm 2}

Step-1: Input all the parameters.

Step-2: Calculate the value of $U$.

Step-3: Solve the problem (20) by taking the transportation cost for first situation $(n k<S+R \leq n k+U)$

Step-4: If $S+R$ Satisfies the condition $n k<S+R \leq n k+U$, then this is the optimal policy and go to Step-7. Otherwise, go to Step-5.

Step-5: Solve the problem (20) by taking the transportation cost for second situation $(n k+U<S+R \leq(n+1) k)$.

Step-6: If $S+R$ Satisfies the condition $n k+U<S+R \leq(n+1) k$, then this is the optimal policy.

Step-7: Stop.

\section{Numerical Example}

To illustrate the model with partially backlogged shortages, a numerical example with the following data has been considered.

$C_{1}=\$ 1.5$ per unit per unit time, $C_{2}=\$ 3$ per unit per unit time, $C_{3}=\$ 8$ per unit, $C_{4}=\$ 250$ per order, $C_{5}=\$ 50$ per advertisement, $C_{t}=\$ 100$ per transport vehicle, $C_{t F}=\$ 1.25$ per unit, $\alpha=0.05, \beta=2$, $\gamma=2.5, a=250, b=0.3, k=100$ units. $L=50 \mathrm{~km}, \delta=1.5, v=0.1$.

Like first model (no-shortage case), the values of different parameters considered here are realistic, through these are not taken from any case study. According to the solution procedure (Algorithm-2), the optimal solution has been obtained with the help of LINGO software for different values of $m$. The optimum values of $n, A, t_{1}, T, S$ and $R$ along with maximum average profit are displayed in Table 3 .

Table 3

Optimal solution for different values of mark-up rate $m$

\begin{tabular}{ccccccc}
\hline$m$ & $A$ & $S$ & $R$ & $t_{1}$ & $T$ & $Z$ \\
\hline 1.25 & 2 & 783.8420 & 16.1580 & 3.7305 & 3.7944 & 197.1620 \\
1.27 & 3 & 878.8360 & 21.1693 & 4.01352 & 4.0949 & 239.7680 \\
1.30 & 3 & 880.2430 & 19.7569 & 4.02088 & 4.09658 & 305.7290 \\
1.32 & 4 & 882.7820 & 17.2182 & 3.9214 & 3.9850 & 350.5670 \\
1.35 & 4 & 883.8263 & 16.1736 & 3.9271 & 3.9867 & 418.4160 \\
\hline
\end{tabular}

\section{Sensitivity Analysis}

For the given example mentioned earlier, sensitivity analysis has been performed to study the effect of changes (under or over estimation) of different parameters like demand, deterioration, inventory cost parameters and mark-up rate on maximum initial stock level, shortage level, cycle length, frequency of advertisement along with the maximum profit of the system. This analysis has been carried out by changing (increasing and decreasing) the parameters from $-20 \%$ to $+20 \%$, taken one or more 
parameters at a time making the other parameters at their more parameters at a time and making the other parameters at their original values. The results of this analysis are shown in Tables 4.

Table 4

Sensitivity analysis with respect to different parameters

\begin{tabular}{|c|c|c|c|c|c|c|c|}
\hline \multirow{2}{*}{ Parameter } & \multirow{2}{*}{$\begin{array}{l}\% \text { changes of } \\
\text { parameters }\end{array}$} & \multirow{2}{*}{$\begin{array}{c}\% \text { changes in } \\
Z^{*}\end{array}$} & \multirow{2}{*}{$A^{*}$} & \multicolumn{4}{|c|}{$\%$ changes in } \\
\hline & & & & $R^{*}$ & $S^{*}$ & $t_{1}^{*}$ & $T^{*}$ \\
\hline \multirow{4}{*}{$C_{1}$} & -20 & 32.64 & 4 & - & 1.47 & -0.64 & -2.47 \\
\hline & -10 & 16.16 & 4 & -65.33 & -12.03 & -1.37 & -2.59 \\
\hline & 10 & -15.45 & 2 & 29.71 & -12.03 & -12.02 & -11.21 \\
\hline & 20 & -29.72 & 2 & 80.04 & -24.52 & -21.83 & -19.64 \\
\hline \multirow{4}{*}{$C_{2}$} & -20 & 0.04 & 3 & 12.62 & -0.28 & -0.27 & -0.02 \\
\hline & -10 & 0.02 & 3 & 5.93 & -0.13 & 1.87 & -0.01 \\
\hline & 10 & -0.02 & 3 & -5.30 & 0.12 & 1.89 & 0.01 \\
\hline & 20 & -0.03 & 3 & -10.06 & 0.23 & 1.90 & 0.02 \\
\hline \multirow{4}{*}{$C_{3}$} & -20 & -69.54 & 1 & 80.90 & -24.54 & -16.13 & -13.75 \\
\hline & -10 & -35.57 & 2 & 28.56 & -12.00 & -8.40 & -7.57 \\
\hline & 10 & 36.99 & 4 & -52.67 & 1.18 & -1.52 & -2.51 \\
\hline & 20 & - & - & - & - & - & - \\
\hline \multirow{4}{*}{$C_{4}$} & -20 & 4.40 & 3 & -35.21 & -10.57 & -10.53 & -11.01 \\
\hline & -10 & 2.16 & 3 & -36.58 & -10.54 & -10.5 & -11.00 \\
\hline & 10 & -2.00 & 3 & -0.57 & 0.01 & 0.01 & 0.00 \\
\hline & 20 & -3.99 & 3 & -1.15 & 0.03 & 0.02 & 0.00 \\
\hline \multirow{4}{*}{$C_{5}$} & -20 & 3.15 & 4 & -7.67 & 0.17 & -2.6 & -2.75 \\
\hline & -10 & 1.51 & 4 & -8.29 & 0.19 & -2.59 & -2.75 \\
\hline & 10 & -1.20 & 3 & -0.34 & 0.01 & 0.01 & 0.00 \\
\hline & 20 & -2.40 & 3 & -0.69 & 0.02 & 0.01 & 0.00 \\
\hline \multirow{4}{*}{$a$} & -20 & -26.81 & 3 & -29.94 & -22.05 & -2.2 & -2.39 \\
\hline & -10 & -13.36 & 3 & -14.85 & -16.14 & -0.97 & -1.06 \\
\hline & 10 & 13.70 & 3 & -22.85 & 0.51 & -8.65 & -9.07 \\
\hline & 20 & 27.73 & 4 & -17.30 & 11.75 & -9.65 & -10.11 \\
\hline \multirow{4}{*}{$b$} & -20 & 0.34 & 3 & -0.67 & 0.02 & -0.23 & -0.24 \\
\hline & -10 & 0.17 & 3 & -0.34 & 0.01 & -0.11 & -0.12 \\
\hline & 10 & -0.17 & 3 & 0.34 & -0.01 & 0.12 & 0.12 \\
\hline & 20 & -0.35 & 3 & 0.68 & -0.02 & 0.23 & 0.24 \\
\hline \multirow{4}{*}{$v$} & -20 & -47.14 & 1 & 110.80 & -47.93 & -47.12 & -43.41 \\
\hline & -10 & - & - & - & - & - & - \\
\hline & 10 & 52.07 & 6 & -100 & 47.69 & 39.37 & 36.8 \\
\hline & 20 & 129.58 & 11 & -100 & 81.77 & 63.57 & 60.55 \\
\hline \multirow{4}{*}{$\alpha$} & -20 & -37.29 & 2 & 88.59 & -36.07 & -37.66 & -34.98 \\
\hline & -10 & -20.47 & 2 & 49.6 & -23.83 & -22.92 & -21.38 \\
\hline & 10 & 25.38 & 4 & -89.9 & 13.38 & 11.72 & 9.83 \\
\hline & 20 & - & - & - & - & - & - \\
\hline \multirow{4}{*}{$\gamma$} & -20 & -2.75 & 2 & -24.69 & -10.81 & -5.72 & -6.01 \\
\hline & -10 & -1.49 & 3 & 2.99 & -0.07 & 1.0 & 1.06 \\
\hline & 10 & 1.76 & 4 & -12.46 & 0.28 & -3.82 & -4.06 \\
\hline & 20 & 3.676 & 4 & -15.89 & -5.32 & -5.06 & -5.36 \\
\hline \multirow{4}{*}{$\delta$} & -20 & 0.02 & 3 & 7.72 & -0.17 & -0.17 & -0.04 \\
\hline & -10 & 0.01 & 3 & 3.71 & -0.08 & -0.08 & -0.02 \\
\hline & 10 & -0.01 & 3 & -3.46 & 0.08 & 0.08 & 0.02 \\
\hline & 20 & -0.02 & 3 & -6.68 & 0.15 & 0.14 & 0.03 \\
\hline
\end{tabular}

\section{Concluding Remarks}

In this paper, two deterministic inventory models for deteriorating items with variable demand dependent on the selling price and the frequency of advertisement of the item have been developed with and without shortages. In the formulation of the model, transportation cost is considered explicitly for replenishing the order quantity. In most of the situations, it is the buyer's cost who must bear the 
transportation cost for transportation of the goods purchased from the supplier. Such costs are either assumed to be fixed and are therefore included in the ordering cost or variable and include in the unit cost of the item. In real-life situations transportation costs of goods are fixed for a finite capacity of a transport mode such as a truck. A fixed cost is incurred when a truck is deployed whether it is utilized fully or partially for a ceiling quantity or more. For quantities less than the ceiling quantity, a uniform rate per unit is charged.

In both models, the demand rate is taken as $D(A, p)=A^{v}(a-b p)$. It is well known that $D(A, p) \propto(a-b p)$ for fixed $A$. But, why should we take $D(A, p) \propto A^{v}$ for fixed values of $p$ ? Generally, the demand of items varies due to the advertisement in the well known media such as Radio, T.V., Newspaper, Magazine, Cinema, etc. The demand of items increases with the increase of frequency of advertisement and is directly proportional to the number of advertisement. Hence, we take $D(A, p) \propto A^{v}$ for fixed $p$.

The present model is also applicable to the problems where the selling prices of the items as well as the advertisement of items affect the demand. It is applicable for fashionable goods also.

The problem of inventory and transportation interactions is a potential field of research. The subject offers a lot of scope for additional work based on what has been presented in this paper. The following can be potential problems that can be studied:

(i) The possibility of single truck supplying the products to more than one go down.

(ii) The possibility of inter-depot transportation can be incorporated from the following points of view.

(a) The inventory - distribution costs can be minimized.

(b) This provides another alternative to deal with the space constraint that is operative at some of the go downs.

(iii)The possibility of mixing up more than one product in the same truck when each factory produces more than one product.

\section{References}

Abad, P.L. (1996). Optimal pricing and lot-sizing under of conditions of perishability and partial backordering, Management Science, 42,1093-1104.

Amutha, R., \& Chandrasekaran, E. (2013). An inventory model for deteriorating items with three parameter weibull deterioration and price dependent demand, Journal of Engineering Research \& Technology, 2(5), 1931-1935.

Anily, S., \& Federgruen, A. (1990). One warehouse multiple retailer systems with vehicle routing costs, Management Science, 36, 32.

Baumol, W. J., \& Vinod, H. C. (1970). An inventory theoretic model of freight transport demand, Management Science, 16, 413 - 421.

Bhunia, A.K., \& Maiti, M. (1998). Deterministic inventory model for deteriorating items with finite rate of replenishment dependent on inventory level, Computers and Operations Research, 25, 9971006.

Bhunia, A.K., \& Maiti, M. (1998). An inventory model of deteriorating items with lot-size dependent replenishment cost and a linear trend in demand, Applied Mathematical Modelling, 23, 301-308.

Buffa, F., \& Munn, J. (1989). A recursive algorithm for order cycle that minimizes logistic cost, Journal of Operational Research Society, 40, 357.

Bhunia, A.K., \& Shaikh, A.A. (2011). A deterministic model for deteriorating items with displayed inventory level dependent demand rate incorporating marketing decision with transportation cost. International Journal of Industrial Engineering Computations, 2(3), 547-562. 
Bhunia A.K., Shaikh, A.A., Maiti, A.K., \& Maiti, M. (2013a). A two warehouse deterministic inventory model for deteriorating items with a linear trend in time dependent demand over finite time horizon by elitist real-coded genetic algorithm. International Journal of Industrial Engineering Computations, 4(2), 241-258.

Bhunia, A.K., Shaikh, A.A., \& Gupta, R.K. (2013b). A study on two-warehouse partially backlogged deteriorating inventory models under inflation via particle swarm optimization, International Journal of System Science. Article in Press.

Chakrabarty, T., Giri, B.C., \& Chaudhuri., K.S. (1998). An EOQ model for items with Weibull distribution deterioration, shortages and trend demand: An extension of Philip's model., Computers \& Operations Research, 25, 649-657.

Constable, G.K., \& Whybark, D.C. (1978). Interactions of transportation and inventory decision, Decision Science, 9, 689.

Covert, R.P., \& Philip, G.C. (1973). An EOQ model for items with Weibull distribution deterioration, American Institute of Industrial Engineering Transactions, 5, 323-326.

Deb, M., \& Chaudhuri, K.S. (1986). An EOQ model for items with finite rate of production and variable rate of deterioration, Opsearch, 23, 175-181.

Emmons, H. (1968). A replenishment model for radioactive nuclide generators. Management Science, 14, 263-273.

Ghare, P., \& Schrader, G. (1963). A model for exponential decaying inventories, Journal of Industrial Engineering, 14, 238-243.

Giri, B.C. Jalan,A.K., \& Chaudhuri K.S. (2003). Economic order quantity model with weibull deteriorating distribution, shortage and ram-type demand, International journal of System Science, 34,237-243.

Ghosh, S.K., \& Chaudhury, K.S. (2004). An order-level inventory model for a deteriorating items with Weibull distribution deterioration, time-quadratic demand and shortages, International Journal of Advanced Modeling and Optimization, 6(1),31-45.

Giri, B.C., C hakrabarty ,T., \& Chaudhuri K.S. (1999). Retailer's optimal policy for perishable product with shortages when supplier offers all-unit quantity and freight cost discounts, Proceeding of National Academy of Sciences, 69(A),III, 315-326.

Giri, B.C. Pal, S., Goswami A., \& Chaudhuri K.S. (1996). An inventory model for deteriorating items with stock-dependent demand rate, European Journal of Operational Research, 95, 604-610.

Goswami, A., \& Chaudhuri, K. S. (1991). An EOQ model for deteriorating items with shortage and a linear trend in demand, Journal of the Operational Research Socity, 42, 1105-1110.

Goyal, S.K., \& Gunasekaran, A. (1995). An integrated production-inventory-marketing model for deteriorating items, Computers \& Industrial Engineering, 28, 755-762.

Kawale, S., \& Bansode. P. (2012). An EPQ model using weibull deterioration for deterioration item with time varying holding cost, International Journal of Science Engineering and Technology Research, 1(4), 29-33.

Krishnaswamy, K. N., Kulkarni, N. G., \& Mathirajan, M. (1995). Inventory models with constraints and changing transportation cost structure, International Journal of Management and Systems, 11, $91-110$.

Kotler, P. (1971). Marketing Decision Making: A Model Building Approach, Holt. Rinehart, Winston, New York.

Ladany, S., \& Sternleib, A. (1974). The intersection of economic ordering quantities and marketing policies, AIIE Trnsactions, 6, 173-175.

Luo, W. (1998). An integrated inventory system for perishable goods with backordering, Computers \& Industrial Engineering, 34, 685 - 693.

Mandal, B. N., \& Phaujdar, S. (1989). An inventory model for deteriorating items and stock-dependent consumption rate, Journal of Operational Research Society, 40, 483 - 488.

Mandal, M., \& Maiti, M. (1997). Inventory model for damageable items with stock-dependent demand and shortages, Opsearch, 34, 156-166. 
Misra, R.B.(1975). Optimum Production lot-size model for a system with deteriorating inventory, International Journal of Production Research, 13, 495-505.

Mondal, B., Bhunia, A.K., \& Maiti, M. (2007). A model of two storage inventory system under stock dependent selling rate incorporating marketing decisions and transportation cost with optimum release rule, Tamsui Oxford Journal of Mathematical Sciences, 23(3), 243-267.

Padmanabhan, G., \& Vrat, P. (1995). EOQ models for perishable items under stock-dependent selling rate, European Journal of Operational Research, 86, 281-292.

Pal, S., Goswami, A., \& Chaudhuri, K.S. (1993). A deterministic inventory model for deteriorating items with stock-dependent demand rate, International Journal of Production Economics, 32, 291 299.

Pal. P, Bhunia, A.K., \& Goyal, S.K. (2007). On optimal partially integrated production and marketing policy with variable demand under flexibility and reliability consideration via Genetic Algorithm. Applied Mathematics and Computation, 188, 525-537.

Pal, A.K., Bhunia, A.K., \& Mukherjee, R.N. (2005). A marketing oriented inventory model with three component demand rate dependent on displayed stock level (DSL), Journal Operational Research Society, 56, 113-118.

Pal, A.K., Bhunia, A.K., \& Mukherjee, R.N. (2006). Optimal lot size model for deteriorating items with demand rate dependent on displayed stock level(DSL) and partial backordering, European Journal of Operational Research, 175, 977-991.

Sarkar, B.R., Mukherje,e. S., \& Balan, C.V. (1997). An order-level lot-size inventory model with inventory-level dependent demand and deterioration, International Journal of Production Economics, 48, 227-236.

Sana, S., Goyal, S.K., \& Chaudhuri, K.S. (2004). A production-inventory model for a deteriorating item with trended demand and shortages, European Journal of Operation Research, 157, 357-371.

Sana, S., Chaudhuri, \& K.S. (2004). On a volume flexible production policy for deteriorating item with stock-dependent demand rate, Nonlinear Phenomena in Complex system,7(1),61-68.

Sharma , V. \& Chaudhary, R.R. (2013). An inventory model for deteriorating items with weibull deterioration with time dependent demand and shortages, Research Journal of Management Sciences, 2, 28-30.

Subramanyam, S., \& Kumaraswamy, S. (1981). EOQ formula under varying marketing policies and conditions, AIIE Transactions, 22, 312-314.

Tripathy.,C. K.,\& Mishra.,U. (2010). An inventory model for weibull deteriorating items with price dependent demand and time-varying holding cost, Applied Mathematical Sciences, 4, 2171-2179

Urban, T.L. (1992). Deterministic inventory models incorporating marketing decisions, Computers \& Industrial Engineering, 22, 85-93. 